one is struck by the fact that the junction of crystal to crystal is not a region of weakness, but is in fact the strongest part of a crystal aggregate. Metals, when forcibly broken in the cold, normally break through the crystals and not along the junctions. There are a large number of experimental facts supporting the view that the gap between two adjacent lattices is bridged by a region of irregularly arranged atoms constituting a layer of amorphous material of excessive strength.

Finally, while in solid solutions we find that the interatomic distances, though varying a few per cent., are roughly constant, in well-defined intermetallic compounds the interatomic distances are sometimes greatly reduced. Thus, in aluminium, the distance is of the order of $4.3 \AA$.U., but in the compound $\mathrm{CuAl}_{2}$, aluminium atoms are found with a centre distance of only $2.42 \AA$.U. In this case, therefore, the nature of the interatomic binding must be quite different, and this probably constitutes the real difference between a compound and a solid solution.

Dr.A.A. Griffith, who followed, pointed out that while at first sight the correlation of data on the breaking strengths of materials with the magnitude of cohesive forces derived by physical method should be comparatively simple, this is far from being the case. One reason for this is that the majority of structural metals are ductile, so that under ordinary stress systems, which almost invariably comprise shearing stresses, the primary failure of the specimen does not involve atomic separation at all but is a failure in shear. Now the mode of collapse of a space-lattice in shear is a subject which has been studied very little by physicists, so that practically no information from the point of view of molecular cohesion is available to engineers.

In the case of certain materials, for example, glass, stone, and hard steel, which exhibit brittle fractures running perpendicular to the direction of the greatest tensile stress, some progress in the subject has been made. Calculations show that in such cases the observed tensile strength is only a small fraction of the calculated molecular tenacity. This discrepancy may be avoided if one assumes the existence of minute cracks in the material fracture being due to the very severe concentration of stress at the corners of the cracks. A formula may be developed which gives results of the right order of magnitude if the radius of the corners of the cracks is taken as two or three molecular spacings. There is another type of fracture obtained with brittle materials, namely, cracks running obliquely to the principal stresses, the best known case being the crushing fracture obtained by simple compression. This may be treated in a somewhat similar manner by the assumption of a large number of minute cracks oriented at random in the material.

With regard to the breakdown of ductile metals, Dr. Griffith and Mr. Lockspeiser have worked out a theory of plastic strain in which the conclusion is reached that plastic strain is simply the external manifestation of phase changes occurring within the material. This view in itself is not new, but the, novelty arises from the fact that deductions are made regarding the number and nature of the distinct phases concerned in the action. The question arises whether it is likely on physical grounds that phase changes can occur as a result of the application of a shear stress; given that this is so, the evidence is more in favour of a resultant change in relative orientation of the atoms than of their configuration.

Prof. Lindemann considered that the assumption made by previous speakers that atoms or molecules are either bonded together, or not bonded, is premature, and cited the fact that fairly definite evidence for intramolecular attraction without definite bonds is to be found in the Sutherland correction to the temperature coefficient of the viscosity of gases, derived by assuming mutual attraction of molecules and verified experimentally.

Prof. R. W. Wood mentioned an interesting experiment requiring explanation. A crystal of rock salt placed in hot water can be immediately bent by the fingers, and remains deformed when removed from the water. The range of temperature over which this has been observed is small and the phenomenon does not occur in the case of immersion in hot oil.

To sum up, the discussion brought out clearly the fact that we are still only at the beginning of a complete explanation of the general phenomena, and there was point in the somewhat facetious remark of Sir Oliver Lodge that it was an extraordinary fact that, after all these years, three important sections of the British Association should be gathered together to discuss why, when one end of a stick is raised from a table, the rest of it also comes up.

\title{
Paris Meeting of the International Council for the Exploration of the Sea.
}

THE sixteenth annual meeting of the International Council for the Exploration of the Sea was held in Paris, on the invitation of the French Government, on October I-5. By the courtesy of the Administrative Council, accommodation was provided for the Council in the Institut Océanographique, founded by the late Prince Albert of Monaco. The following countries, members of the Council, were represented : Belgium, Denmark, Esthonia (for the first time), Finland, France, Great Britain, Holland, Norway, Portugal and Sweden. Representatives of the Irish Free State attended as visitors.

The usual committees and sections for hydrography, plankton, statistics, herring, plaice, cod and haddock, limnology, the Baltic Sea and the Atlantic Slope were assembled, and a new committee, named the North Atlantic Committee, was formed.

It is important to observe that all committees and sections are now instructed to formulate precise programmes of work, allotting to each country concerned a definite part in the programme, which it undertakes to perform. Each country is called upon afterwards to report to the Council on the work it has carried out in accordance with these undertakings, and the effect of these reports is embodied in a general progress report submitted to the Council at each meeting. The tendency to present excellent but unrealisable recommendations is thus discouraged.

For the most part the committees reaffirmed their existing programmes in respect of which generally satisfactory progress was reported. It will be observed that there are three committees for the study of particular fishes. The Plaice Committee, the recommendations of which for the protection of the plaice fisheries were adopted by the Council in I922, and are now under the consideration of the participating Governments, is chiefly engaged in watching developments and checking its own conclusions.

The intensive investigations of the plaice having thus come to a pause, the study of the herring, cod and haddock is being vigorously prosecuted, in accordance with comprehensive practical programmes adopted in I92 I, and afterwards modified in the light of experience. Unfortunately, owing to the difficulties of the time, many of the countries concerned are 
inadequately equipped for work at sea, and the bulk of the sea work falls on England and Scotland. It is particularly regrettable that Norway, to which, in the person of Dr. Einar Lea, is entrusted the leadership of the herring investigations, has not yet been able again to equip a ship for deep-sea research. The herring investigations at their present stage involve, to a considerable extent, the application to the investigation of North Sea herrings of the methods employed by Hjort and Lea in their investigations of the Norwegian herrings. With a view to the standardisation of these methods, English and Scottish naturalists are studying under Hjort and Lea at Christiania.

The Cod and Haddock Committee is under the convenership of Dr. E. S. Russell; but the work of direction is divided between England and Scotland, the latter being responsible, through Dr. Bowman, for dealing with haddock material and the former with cod.

The proposal to form a North Atlantic Committee was approved after a lengthy debate in a special committee of the whole Council. On one hand it was felt that the committees were already dangerously numerous, that the fishes which would come under examination by the North Atlantic Committee were mainly those actually being investigated by other committees, and that a further extension of the principle of geographical division of work already accepted in the formation of the Committee of the Atlantic Slope and the Baltic Committee created the risk of redundancy unless it could be shown that the area to be studied was, in respect of some at least of its features, self-contained, and presented phenomena peculiar to itself. It was more particularly on the last-named ground that the Danish Commission in a memorandum submitted to the Council supported their proposal, which had for its principal object the study of the fisheries of Iceland and Faroe. They pointed out that the Icelandic fisheries in particular, and the physical conditions governing those fisheries, presented peculiarities which merited individual study. They summarised their argument in the following terms: "In regard to fishery biology as well as hydrography the various parts of the Icelandic area are extremely dissimilar. There is in fact a greater difference in this respect between South and East Iceland than between South Iceland and the Faroes, or, indeed, between South Iceland and Ireland."

The Council eventually resolved to form a North Atlantic Committee for research north of the latitude of Rockall, and, while instructing the Committee to commence work in the area suggested in the Danish Commission's memorandum, urged it to keep in mind the importance of extending its area of observations particularly to the eastern and northern parts of the Norwegian Sea. The Committee was further instructed to arrange its programme in consultation with the other committees concerned. The programme adopted, in accordance with this instruction, provides for the hydrographical and biological investigation of the region, with special reference to cod, haddock, halibut, plaice and herring. The leadership of the work was entrusted to Dr. Johs. Schmidt. The greater part of the sea work will be carried out by means of the Dana, but France will make provision for observations by means of cruisers stationed at Iceland, and Scotland will conduct hydrographical-biological cruises from the west of Scotland to the Faroes. England will assist with fishery statistics and measurements.

An interesting discussion arose in connexion with the work of the Statistical Committee, of which Prof.
D'Arcy Thompson is permanent chairman. The British delegates were instructed to endeavour to secure the general adoption of more effective and, in particular, more uniform statistical methods, such as are in use in Great Britain. Owing to the lack of uniformity of method, it is at present most difficult to present in the Bulletin statistics which afford a true indication of the actual condition of the fisheries in a given region or part of a region, and of the variations of the stock from year to year. For example, different countries while using the same regional nomenclature have different conceptions of the limits of the regions, and the majority of them are not able to give any accurate idea of the precise locality fished or of the amount of fish of any given species-or of fish of all kinds-taken per unit of time; e.g., the quantity of fish taken in a given area in roo hours' fishing. Statistics which do not present a picture of the distribution of the stock in time and space are of little value to the scientific worker, and it is for scientific rather than for commercial purposes that the International Council should collect and publish statistics. It was readily agreed by the Statistical Committee that uniformity must be secured in the matter of the designation of statistical regions and areas; but it was impossible in the time at the disposal of the Committee to arrive at unanimity as to the limits by which the regions should be defined. This question was accordingly referred to a special sub-committee which was requested to report to the committee before the next meeting of the Council. The question of getting detailed statistics of locality of capture, i.e. fishing ground, and of the relation of fishing power to catch of fish, proved to be one of ways and means, and the reply of most countries was that they had not the staff for the collection of such statistics on the scale adopted in Great Britain. Eventually it was agreed that each country should endeavour to collect statistics from some of its vessels according to the methods employed in England, and an undertaking was given on behalf of the English Department, being the best equipped for the purpose, that the Department would for the present work up the data if sent to them.

The work of the Committee of the Atlantic Slope continues to be under the leadership of Dr. Edouard le Danois. The English Department is not yet in a position to take part in the sea work, but it is hoped that the Marine Biological Association will continue the assistance which it has given in the past.

A memorandum was submitted to the Council by Prof. Otto Pettersson and Commodore C. F. Drechsel advocating an international expedition to study the system of currents of the great oceans, with reference especially, to quote from the memorandum, to the following questions :

"( 1 ) Whether the changes we observe in the fish life of our seas correspond with the changes we observe in the current system of the ocean; and

"(2) Whether these changes are of periodic nature."

The authors of the memorandum, which gave rise to a most interesting debate, urged that advantage should be taken of the fact that the late Prince of Monaco's yacht Hirondelle was for sale to secure and equip this vessel and to employ it for four years in an investigation of the questions above stated. They invited the Council to support the proposal, which they desired to submit, with the authority of the Council, to the governments of the civilised world, in the hope of securing the co-operation of all these governments in the enterprise. They pointed out that if the proposal secured world-wide support the actual cost to any individual country would be comparatively small. In the debate which took place 
upon the memorandum it was freely recognised that the practical difficulties in the way of the realisation of such a scheme would be great. The Council, however, eventually passed a resolution recording its opinion that an increased knowledge of the ocean systems was not merely of scientific interest but of practical importance for the explanation and the forecasting of phenomena affecting life both in the sea and on land, that such an investigation must necessarily be extended over many years, but that it could usefully be initiated by a preliminary reconnaissance on the lines suggested in the memorandum. The Council therefore recommended the proposals to the tavourable consideration of the governments and scientific institutions of all countries. In its resolution the Council was careful to point out that such an undertaking as this went far beyond the limits both of its resources and of its mandate, and must be regarded as a distinct and world-wide enterprise. It affirmed, however, its readiness, should the proposal meet with adequate support, to undertake the general direction of the work. It was generally felt that there was no other existing organisation equally competent.

The next meeting of the Council will be held, as usual, in Copenhagen.

\section{Electrometric Methods in Analytical Chemistry. ${ }^{1}$}

$\mathrm{T}^{\mathrm{H}}$

HIRTY years ago electrometric methods of analysis were too complex for technical purposes, but the importance of " hydrogen ion concentration " re-directed attention to them, with resulting simplification.

When a piece of silver is dipped in a solution, a solution pressure is exerted, silver ions being driven into solution until equilibrium is established between the osmotic pressure of the ions in the solution and the solution pressure of the silver. Hydrogen behaves similarly, as does chlorine. It thus becomes possible to find a suitable electrode for any reaction giving a change in valency.

In the reduction of potassium permanganate the electrolytic potential $(\epsilon)$ is given by the formula :

$$
\epsilon=\epsilon_{0}+\frac{0 \cdot 058}{n} \log \frac{\left[\mathrm{Mn}^{\prime \prime}\right]}{[\mathrm{H}]^{8}\left[\mathrm{MnO}_{4}^{\prime \prime}\right]}
$$

If the $\log$ expression is kept constant there results a normal electrode. In practice such an electrode must be combined with one which changes its potential during the course of the titration. It is possible to titrate silver with halides, sulphides, cyanides, and thiocyanates, and vice versa. An interesting feature is the possibility of the simultaneous titration of halides in admixture, there being successive falls of potential as each is reacted upon by the silver solution. In the presence of protective colloids there is of course no apparent precipitation. It is interesting to note that this does not interfere with the titration.

Protective colloids stop crystal growth and consequently increase somewhat the solubility of the precipitate. This solubility is usually so low that an increase of even 100 per cent. does not lead to appreciable errors. It thus becomes possible to estimate directly small amounts of metal in, say, blood serum. Certain organic substances, such as silver salvarsan, contain silver in such a form that it is not acted upon by chlorides. Use is made of sulphides, the diameters of the ions of which are such that monovalent cations of the dimensions of silver ions are unable to resist their influence. Ionic dimensions play an important part in determining the insolubility of certain precipitates.

Titrating zinc in acid solution with potassium ferrocyanide, curves not of the usual bi-logarithmic type are obtained. The abnormality is due to small amounts of ferric iron. On filtering through aluminium powder, reduction to ferrous iron takes place and normal curves are obtained.

For nickel and cobalt in admixture electrometric

1 Synopsis of a paper presented to the Manchester Sections of the Society of Chemical Industry, Society of Dyers and Colourists, Institute of Chemistry, and the Manchester Literary and Philosophical Society, on November 2, by Prof. W. D. Treadwell of the Technical Highschool, Zürich. titration with potassium cyanide is the best. The complex ions " $\mathrm{Ni}(\mathrm{CN})_{4}$ and $" \mathrm{Co}(\mathrm{OH})(\mathrm{CN})_{5}$ are formed. The curves obtained yield no evidence of the formation of intermediate complexes.

For oxidation and reduction titrations a platinised electrode is most satisfactory. Titanium may be estimated very accurately in the presence of iron after filtration through a cadmium powder filter in an atmosphere of carbon dioxide and subsequent titration with potassium dichromate. If a blank electrode is employed it is liable to become passive at the end of the titration, producing a sudden drop of potential instead of a rise.

With regard to dye-stuffs there is little to add to the excellent methods of Knecht, but where electrometric methods are used, frequent use is made of cadmium filters for reduction. Titrating primary amines in acid solution with sodium nitrite a sudden rise in potential is obtained with the first drop in excess of the latter.

For the estimation of free halogens an example was given of the estimation of $O \cdot I$ per cent. of bromine in sodium chlorate by distillation with hydrochloric acid followed by titration with arsenious acid.

An especially resistant electrode for the estimation of insoluble oxides is obtained by passing an alloy of 90 per cent. gold with ro per cent. copper through a bunsen flame, when it becomes covered with a thin layer of a copper oxide.

In conductivity titrations the conductivity usually changes sharply enough to indicate the end-point, but where weak acids are concerned care must be exercised. Use is made of a Wheatstone bridge and an alternating current. The millivoltmeter may still be used by the introduction of a rotating switch, the poles in the solution being changed six to eight times a second. The current then becomes virtually a continuous one. The method is the best one for alkaloids and also for water in organic liquids. An example of the latter is the estimation of water in so-called absolute alcohol. A salt is added which completely ionises in aqueous solution, e.g. potassium perchlorate. The alcohol is rapidly stirred and the conductivity measured. The solubility of the salt is a linear function of the water present, and from an examination of the curves obtained its content may be deduced. Conductivity methods are excellent for determining and comparing the hardness of waters.

The last few years has seen the replacement of electro-deposition methods by titration methods, and very accurate results may now be obtained even with the simplest equipment. The behaviour of titration electrodes requires further study, and from the work now being carried out on surface adsorption and surface actions in general, much progress may be expected in the future.
L. G. R. 